\title{
High Speed (100G) Access Networks
}

\author{
Tomas Horvath, Member, IEEE, Jan Chlapek, Petr Munster, Member, IEEE, OSA, Josef Vojtech, Senior \\ Member, IEEE, OSA, Miloslav Filka, Senior Member, IEEE
}

\begin{abstract}
Passive optical networks are currently the most promising solution for access networks. Increasing bandwidth requirements and big data applications need a huge bandwidth. Nowadays, gigabit passive optical networks do not seem to be suitable for these purposes. This paper is focused on describing the development, parameters and needs for High Speed Access Networks (such as 100G EPON). The simulations with current wavelengths plans are presented. For simulations we used VPITransmissionMaker ${ }^{\mathrm{TM}}$ 9.7. Our goal was to create a rudimentary bidirectional PON system with one ONU and do several simulation scenarios by artificially increasing loss in a splitter for simulating more ONUs. Our following results consist of BER values and eye diagrams for each simulation scenario and proof that 100G EPON networks are most promising networks for the future. We proved that the 100G-EPON networks fully support the basic and currently used split ratios. We also created a two-way communication model and evaluated the obtained data from the bit error-rate and system reach point of view. The entire model was compared with the final version of NG-PON2.
\end{abstract}

Index Terms-Next Generation EPON, 100G EPON, VPIphotonics, simulations.

\section{INTRODUCTION}

A LTHOUGH Internet connection speeds over $1 \mathrm{Gbit} / \mathrm{s}$ seem insignificant for the end users for the time being, according to some speculations in 5 year's time several Telecom providers might face problems with insufficient transfer capacities in their access networks [1].

The most significant influences for the increase of Internet connection speeds are especially growing number of connected devices per user and popular modern trends like fast cloud storage or $4 \mathrm{~K}$ multimedia content streaming with platforms such as Netflix, HBO GO, You Tube etc.

Due to fast grow of demand for fast Internet connection, a solution must be created in time for providers to be able to increase transfer rates of their distribution networks [1]. That is why a study was launched in 2014 with an objective to investigate technical requirements and economic feasibility for a next generation EPON (Ethernet Passive Optical Network). This study has eventually resulted in establishing a task group with a goal to create specification for a new EPON standard.

Primary goals of the standard [1]:

Manuscript received March 30, 2018; revised August 26, 2018. Date of publication September 18, 2018. Prof. Tianhua Xu has been coordinating the review of this manuscript and approved it for publication.

Tomas Horvath, Jan Chlapek, Petr Munster, and Miloslav Filka are with the Department of Telecommunications, Brno University of Technology, Brno, Czech Republic, 61600 (e-mail: xchlap02@stud.feec.vutbr.cz, horvath, munster, filka@feec.vutbr.cz)

Tomas Horvath, Petr Munster, Josef Vojtech are with CESNET a.l.e., Department of Optical Networks, Zikova 4, Prague, Czech Republic (e-mail: horvath, munster@cesnet.cz)

Digital Object Identifier (DOI): 10.24138/jcomss.v14i3.523
- Use of Point-to-Multipoint access network topology,

- specification that would enable the physical layer to work with both symmetric and asymmetric variants over one single mode optical fibre,

- frame loss ratio or BER (Bit Error Rate) better or equal to $10^{-12}$

- coexistence with 10G-EPON (symmetric).

The main contribution of this work is the simulation of the current designs of $100 \mathrm{Gbit} / \mathrm{s}$ networks. The standardization of these networks is currently under IEEE. The proposals and pre-final topology + parameters are now available. The stateof-the-art in the theoretical part of the development of these technologies is described in detail in [2]. Next, authors of [3], [4] focused on the possibilities in 100G networks line codes. In their work, they did not consider the previously-mentioned critical parameter: division ratio. Their primary goal was to evaluate the channel spacing (100GEPON networks will use multiple wavelengths), and the line codes in use. As mentioned previously, the current form of the 100G EPON network may not be final one. The publication [5] presents possibilities for using dynamic bandwidth allocation for end-units with a bit rate of: 25; 50; and $100 \mathrm{Gbit} / \mathrm{s}$. The main goal of our study was to create an Optical Access Simulation Network that reflects the currently available parameters, to assess the reach of the system for commonly used division ratios, and to evaluate the deployment of the 100G-EPON network in comparison with NG-PON2 networks that do achieve transmission rates of up to $40 \mathrm{Gbit} / \mathrm{s}$. In addition, our simulations do not focus only on the downstream direction but also simulate the bi-directional transmission

The rest of this paper is structured as follows. Section II describes the related works. Section III and Section IV introduce architecture of $100 \mathrm{GEPON}$ and the wavelength plans. Section V deals with a simulation scheme of $100 \mathrm{GEPON}$ and Section VI discusses the results of simulation. Section VII compares 100GEPON networks with NG-PON2 networks. Finally, Section VIII concludes the paper.

\section{RELATED WORKS}

Authors in [3] investigate transceiver designs for NRZ (Non Return to Zero), ODB (Optical Dual Binary) and PAM4 (Pulse Amplitude Modulation) modulation based on high power budget scenario.

The work [6] experimentally demonstrates the modulation, fibre transmission and reception of $25 \mathrm{Gbit} / \mathrm{s}$ signal on $10 \mathrm{G}$ optical devices for three types of modulation NRZ, PAM4 and ODB. Concerning the cost of application, dispersion and loss of budget, NRZ came out as the recommended 
modulation mainly for its maturity, best launch power and receiver sensitivity and cost.

Asymmetrical TWDM-PON (Time and Wavelength Division Multiplexed PON) with $(4 \times 25) \mathrm{Gbit} / \mathrm{s}$ downstream DSB OFDM (Double side band Orthogonal Frequency Division Multiplexing) and $(4 \times 10) \mathrm{Gbit} / \mathrm{s}$ upstream OOK (On-Off Keying) modulation experimentally demonstrates TWDM scheme based on Double side-band OFDM with 16 QAM (Quadrature amplitude modulation) mapping for downstream transmission and on-off key modulation for upstream transfer [7]. Their work achieve a $35.5 \mathrm{~dB}$ power budget for downstream and thanks to simplified upstream they were able to achieve a cost efficient upstream transmission with $42.5 \mathrm{~dB}$ power budget.

The researchers in [4] and the collective investigate a transmission of $28 \mathrm{Gbit} / \mathrm{s}$ for NRZ, duo-binary and PAM4 in Experimental Study of NRZ, Duo-binary and PAM4 in O-band DML-based (Directly Modulated Laser) 100GEPON. Their results indicate that NRZ outperforms both modulation formats in receiver sensitivity and that the transmission was achieved without any pre amplification which makes it a cost-efficient solution for $100 \mathrm{G} \mathrm{EPON}$.

Practical demonstration of $25 \mathrm{Gbit} / \mathrm{s}$ NRZ transmission for $100 \mathrm{G}$ EPON is published in [8]. It is demonstrated there that $35 \mathrm{~dB}$ power budget for PR30 (total reach of system is up to $30 \mathrm{~km}$ ) class is achievable and that $25 \mathrm{G}$ APD (Avalanche Photodiode) solution has lower cost and complexity with better performance compared to $10 \mathrm{G}$ APD receivers.

Symmetric 100GEPON was also demonstrated by using $10 \mathrm{G}$ optical devices in [9]. They demonstrate symmetric $100 \mathrm{GEPON}$ using $(4 \times 25) \mathrm{Gbit} / \mathrm{s}$ capacity on both directions using NRZ in O-band.

In article [10] researchers focused on demonstrating a symmetric $100 \mathrm{Gbit} / \mathrm{s}$ TWDM-PON in O-Band using NRZ-OOK format with budget loss of $32 \mathrm{~dB}$ and DSF (Dispersion Shifted Fiber). They used 10G-Class optical devices for both the transmitter and receiver and also SOA-based pre-amplification.

Novel technique for an increase of access points in a WDM-PON network integrated in a $100 \mathrm{GHz}$ radio-over-fiber (RoF) was described by researchers in [11]. They used MRR (Microring Resonator) system to generate optical carriers for transmission of four OFDM (Orthogonal Frequency Division Multiplexing) signals and proved that transmission of four OFDM channels is feasible for a SSMF (Standard Single Mode Fiber) of $25 \mathrm{~km}$ of length.

\section{ARCHITECTURE}

Architecturally, the focus was set to divide the standard into three generations so the development process would be eased, and the standard made to last longer than its predecessors. From this stand point a so called $1+3$ architecture was adopted [14].

The base of this standard would be a wavelength pair with both symmetric transfer speed of $25 \mathrm{Gbit} / \mathrm{s}$ or asymmetric transfer speeds of 25/10 Gbit/s by using coexistence with $10 \mathrm{G}$ EPON (symmetric variant) for the upstream transfer speed [1]. Higher speeds in future generations of the standard would be achieved by channel bonding up to 4 additional wavelengths to get transfer speeds of $100 \mathrm{Gbit} / \mathrm{s}$ [1].
The main benefit of this architecture is the fact that although an OLT (Optical Line Termination) in an optical distribution network would be upgraded to a newer generation, featuring more channel bonded wavelengths, older ONUs (Optical Network Units) would remain compatible with the optical distribution network with before upgrade specifications as represented in Fig. 1.

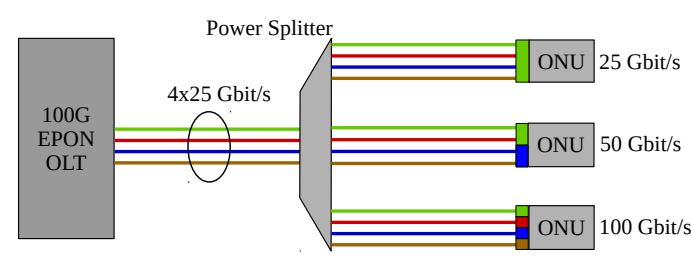

Fig. 1. Channel bonding with $100 \mathrm{G}$ EPON

One of the most important aspects of the new standard is a choice of wavelengths for the optical transmitters. Since the goal for the standard is to remain compatible with 10GEPON efforts are being put to come up with a wavelength plan with regards to power, cost and results based on their early simulations [14].

Since January 2016, 6 plans were presented with wavelength selection for downstream and upstream. In November 2016, a $1+3$ architecture adoption cut of all plans considering a $1+4$ architecture where the first generation of the standard were to be eventually split off and made stand alone as shown in Fig. 2 [14].

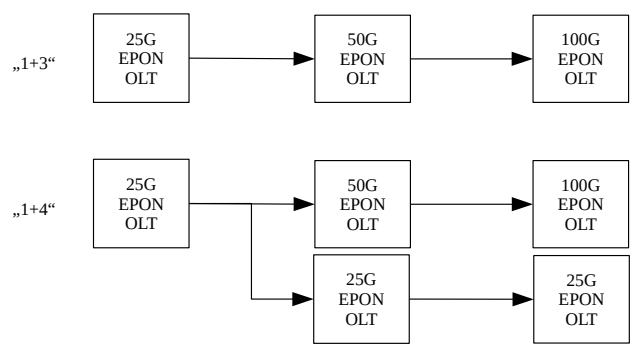

Fig. 2. Block scheme of EPON architecture [14]

\section{WAVELENGTH Plans}

\section{A. Plan A}

In Plan A all wave pairs are considered in O-Band for easy implementation of NRZ line code thanks to low dispersion. Band also supports both DML and EML (Electroabsorption modulated laser) and some optical resources could be reused according to older standards. Coexistence with 10G-EPON would be through WDM, however due to low guard band between the standards wavelengths, additional optical filters would be needed to prevent possible crosstalk in upstream. [14] 


\section{B. Plan B}

This plan follows plan A in considering all wave pairs in Oband however aims at making the first-generation deployment more cost efficient. These cost savings would be achieved using uncooled DML lasers with $20 \mathrm{~nm}$ bandwidth for upstream. As 10G-EPON occupies this wavelength for upstream as well coexistence would be possible only through TDM. [14]

\section{Plan D}

This plan follows plan A in upstream however for downstream wavelengths it considers C-band so that it could benefit from low attenuation, low cost optical diplexers and EDFA on OLT side. Main disadvantage in C-band is higher dispersion, however research shows that transfer under $10 \mathrm{~km}$ are achievable in C-band without any dispersion compensation needed and since only a small percentage of PONs are over $10 \mathrm{~km}$ the increase of costs of other technology would not be too high for most PONs. [14]

TABLE I

COMPARISON OF 10G-EPON AND 100G EPON

\begin{tabular}{|l|l|l|}
\hline PON Type & 10G-EPON & 100G Epon (3.gen) \\
\hline Designation [-] & $802.3 \mathrm{av}$ & $802.3 \mathrm{ca}$ \\
\hline Downstream [Gbit/s] & 10.3125 & $100(4 \times 25)$ \\
\hline Upstream [Gbit/s] & 10.3125 & $100(4 \times 25)$ \\
\hline & & plan A $-1335-1354$ \\
\hline Downstream Wavelengths [nm] & $1575-1580$ & plan B - 1329-1353 \\
\hline & & plan D - 1532-1558 \\
\hline & & plan A - 1290-1304 \\
\hline Upstream Wavelengths [nm] & $1260-1280$ & plan B $-1260-1302$ \\
\hline & & plan D - 1290-1304 \\
\hline Line code & $64 \mathrm{~B} / 66 \mathrm{~B}$ & NRZ \\
\hline Security [-] & bidirectional & bidirectional \\
\hline Line Protocol [-] & Ethernet & Ethernet \\
\hline Max. Split Ratio [-] & $1: 32$ & $1: 32$ \\
\hline Max. Reach [km] & 20 & 20 \\
\hline FEC [-] & RS $(248,216)$ & yes \\
\hline
\end{tabular}

\section{Simulation of $100 \mathrm{G}$ EPON}

Simulation scenarios were made in a simulation software VPITransmissionMaker ${ }^{\mathrm{TM}} 9.7$ which is a part of a complex solution of professional simulation tools of VPIPhotonics company [16].

Each simulation model is a bidirectional simulation scenario. The model can be divided into three sections: a transmitter, a distribution network, a receiver and vice versa. The goal of the simulations was to get BER values and eye diagrams for split ratios in range from 1:4 to $1: 128$ for distances of 12 through $20 \mathrm{~km}$ at $2 \mathrm{~km}$ increments and then for $30 \mathrm{~km}$. Simulation model is shown in Fig. 3.

An optical transmitter consists of PRBS (Pseudorandom Binary Sequence), NRZ coder, Mach-Zehnder Modulator and a continuous wave laser. Main used parameters: Emission frequency, power output and extinction ratio in MZM. PRBS was set to random. NRZ (Non-return-to-zero) is the basic modulation format used in fibre optic communication system due to its simplicity and narrow bandwidth. It is simplest modulation format where binary 1 or 0 represents one bit. NRZ is not suitable for high speed optical networks but compare to high order modulation formats longer distances (or higher optical power budget) can be achieved, on the other hand. Another modulation format, RZ (Return-to-zero) can use different forms (e.g. RZ with $50 \%$ duty cycle, RZ with $33 \%$ duty cycle, or carrier-suppressed RZ) and compare to NRZ has higher dispersion tolerance. High-order modulation formats (QAM, PSK, etc.) enable transmission of higher speeds compare to basic modulation formats. Disadvantage of these systems is complex modulators and demodulators, and also DSP which increase the price of the systems. Also optical power budget is not so high and hence these systems are currently not suitable for PON networks. [13]

Optical distribution network consists of a $10 \mathrm{~km}$ long optical fibre leading to a power splitter and a second fibre with incrementally added length up to $30 \mathrm{~km}$ in total. The power splitter in our case performs as an ideal power splitter. Split ratios were simulated by adding a loss module with attenuation corresponding with table values of split losses.

Receiver was simplified by using a "RX_OOK_BER" module combining several functions. It implements a complete receiver apparatus consisting of a photo-diode, filters and clock recovery. A module for BER calculations is also implemented. From this module results were displayed using spectral analyser and BER output graph. BER and eye diagrams were taken for each received lambda separately.

The FEC (Forward Error Correction) could not be implemented as the software does not support Reed Solomon codes used in PONs in this version.

The simulation was made during the time when no definitive wavelength plan was chosen. Dispersion was one the key elements discussed at the time by the task force. In our simulation we followed the plan with all wavelength based in O-band where the dispersion compensation was not needed. Dispersion tolerance $\mathrm{S} / \mathrm{L} / \mathrm{C}$ band was further examined by the task force and was found that ranges up to $10 \mathrm{~km}$ would also be possible without any dispersion compensation [12].

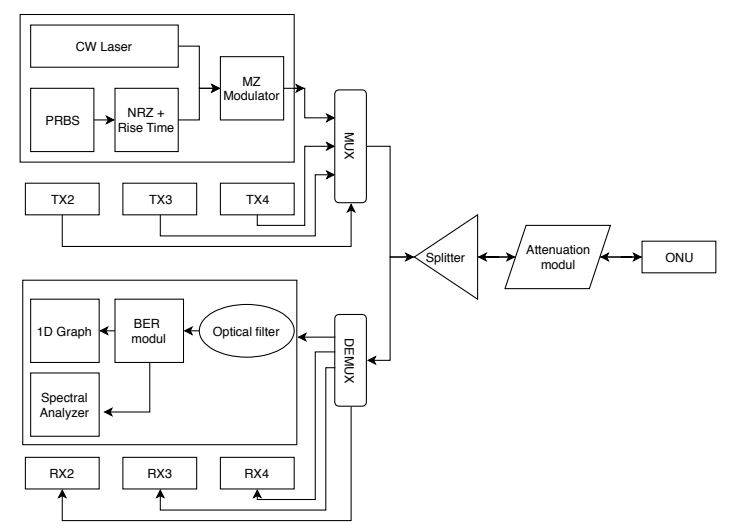

Fig. 3. 100G EPON Simulation Model

As the standard is in early development stages and will not be finished sooner than 2019, many details are not finalized yet. Since there are no final materials on wavelength 
plan, ODN (Optical Distribution Network) classes or transmitter/receiver specifications, simulation model was designed based on working materials from the task force and some specifications from $10 \mathrm{G}$ EPON standard. Used parameters for the 100G EPON simulation are mention in Table. II.

TABLE II

PRESUMEd PARAMETERS OF PR30 Class

\begin{tabular}{|l|l|l|}
\hline Parameters & OLT & ONU \\
\hline Max. Output & $+5 \mathrm{dBm}$ & $+9 \mathrm{dBm}$ \\
\hline Min. Output & $+2 \mathrm{dBm}$ & $+4 \mathrm{dBm}$ \\
\hline Max. Loss & $29 \mathrm{~dB}$ & $29 \mathrm{~dB}$ \\
\hline Min. Loss & $14 \mathrm{~dB}$ & $15 \mathrm{~dB}$ \\
\hline Min. Extinction ratio & $9 \mathrm{~dB}$ & $6 \mathrm{~dB}$ \\
\hline Receiver sensitivity & $-26 \mathrm{dBm}$ & $-28 \mathrm{dBm}$ \\
\hline Lambda 1 & $1335 \mathrm{~nm}$ & $1290 \mathrm{~nm}$ \\
\hline Lambda 2 & $1344 \mathrm{~nm}$ & $1294 \mathrm{~nm}$ \\
\hline Lambda 3 & $1349 \mathrm{~nm}$ & $1299 \mathrm{~nm}$ \\
\hline Lambda 4 & $1354 \mathrm{~nm}$ & $1303 \mathrm{~nm}$ \\
\hline Split ratio & $1: 32$ & $1: 32$ \\
\hline Line code & NRZ & NRZ \\
\hline Max. Reach & $20 \mathrm{~km}$ & $20 \mathrm{~km}$ \\
\hline BER & $10^{-3}$ & $10^{-4}$ \\
\hline
\end{tabular}

\section{RESUlts OF 100G EPON SiMULATION}

Results of each simulation scenario are BER values and eye diagrams for all split ratios, fibre lengths and individual lambdas for both downstream and upstream direction. As the simulation model is considered, ideal results are only affected by losses, split ratios and dispersion settings.

Eye diagrams for three fibre lengths 12,16 and $20 \mathrm{~km}$ were put overlapping into a single eye diagram. No distinguishable signal degradation can be observed for split ratio 1:4 as shown in Fig. 4.

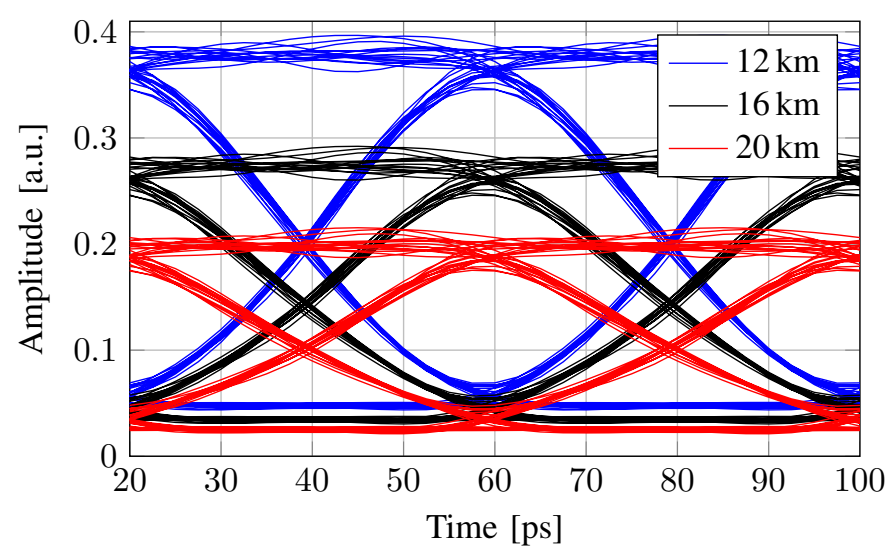

Fig. 4. Downstream split ratio of 1:4

First observable degradation starts at split ratio 1:16 where both jitter and ISI (Intersymbol Inteference) are increasing. This increase is also closely followed in BER increase as can be seen in Fig. 6 .

For testing purposes, 1:64 and 1:128 split ratios were attempted, however due to strong signal degradation it is unlikely that these split ratios could be used for PR30 class even with FEC for anything but low reach fibre lengths. Gained eye diagrams for 1:64 can be seen on Fig.5.

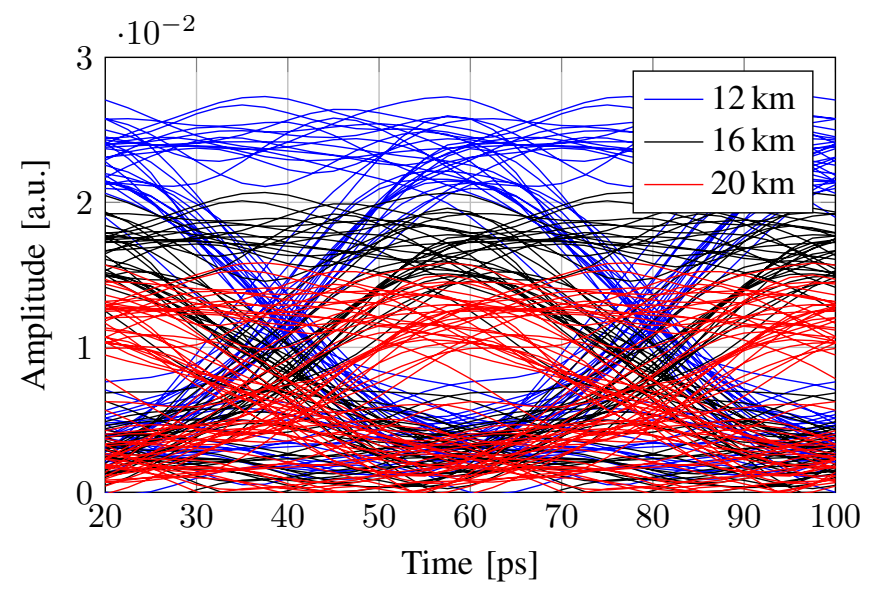

Fig. 5. Downstream split ratio of 1:64

Gained BER values are closely following observable results of eye diagrams. As shown in Fig. 6 split ratios of 1:4 and 1:8 are nearly without any difference with first noticeable increases in BER with split ratio of $1: 16$. The graph shows split ratio $1: 32$ to be also viable, however it is cutting it close for $20 \mathrm{~km}$ fibre length. It is unlikely that higher split ratios would be possible for fibre lengths higher than $10 \mathrm{~km}$ even with FEC implemented.

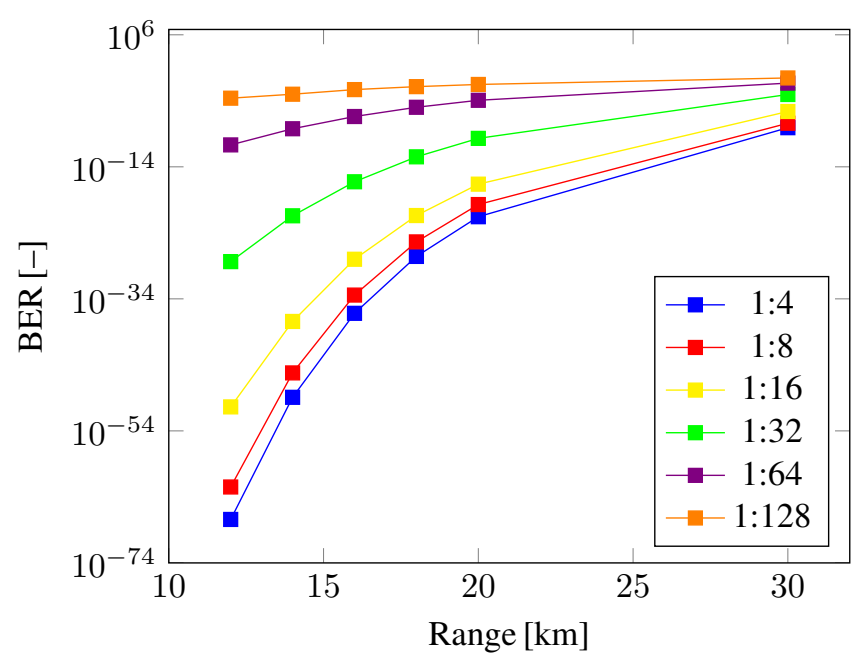

Fig. 6. BER Downstream Dependency on Reach in 100G EPON

When comparing BER with upstream direction in Fig. 7 we can see subtle differences especially noticeable for split ratio 1:32 confirming it to be a limit for PR30 class. It is important to note that used parameters for this simulation are not final parameters for PR30 class for this standard.

\section{NG-PON2 COMPARISON}

For comparison purposes, a NG-PON2 simulation was also conducted using the same simulation model as $100 \mathrm{EPON}$. The parameters in this simulation were based on N1 budget class (14-29 dB). The goal was to compare these Next Gen PONs in terms of their results for deployment purposes, however cost regards where not factored in as the final cost difference will not be known until both standards are finalized. 


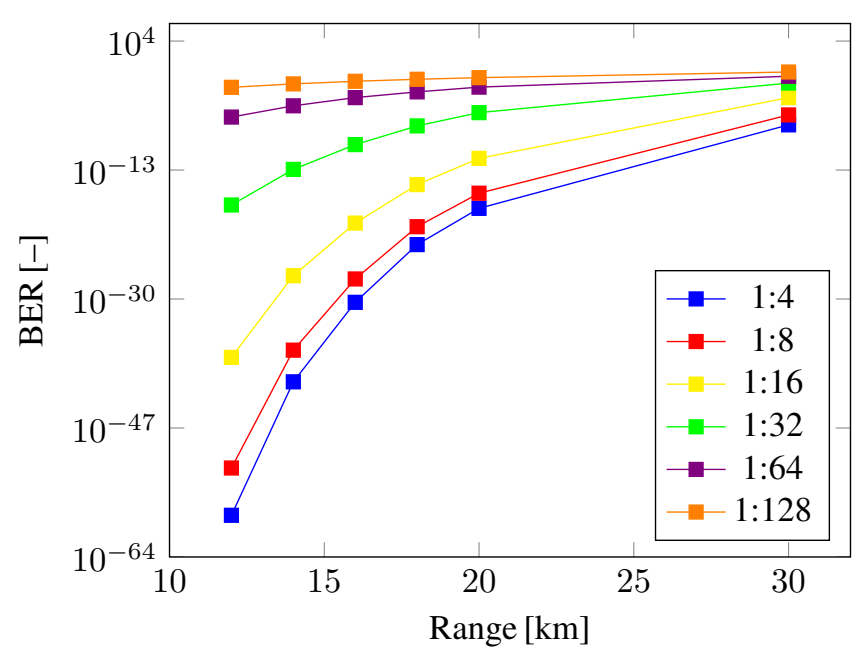

Fig. 7. BER Upstream Dependency on Reach in 100GEPON

Parameters for the NG-PON2 simulation were taken from $\mathrm{N} 1$ class specification as shown in III.

TABLE III

NG-PON2 PARAMETERS

\begin{tabular}{|l|l|l|}
\hline Parameters & OLT & ONU \\
\hline Max. Output & $+6 \mathrm{dBm}$ & $+9 \mathrm{dBm}$ \\
\hline Min. Output & $+2 \mathrm{dBm}$ & $+4 \mathrm{dBm}$ \\
\hline Max. Loss & $29 \mathrm{~dB}$ & $29 \mathrm{~dB}$ \\
\hline Min. Loss & $14 \mathrm{~dB}$ & $14 \mathrm{~dB}$ \\
\hline Min. Extinction ratio & $8.2 \mathrm{~dB}$ & $8.2 \mathrm{~dB}$ \\
\hline Receiver sensitivity & $-26.5 \mathrm{dBm}$ & $-28 \mathrm{dBm}$ \\
\hline Lambda 1 & $1596 \mathrm{~nm}$ & $1532 \mathrm{~nm}$ \\
\hline Lambda 2 & $1597 \mathrm{~nm}$ & $1535 \mathrm{~nm}$ \\
\hline Lambda 3 & $1598 \mathrm{~nm}$ & $1538 \mathrm{~nm}$ \\
\hline Lambda 4 & $1599 \mathrm{~nm}$ & $1541 \mathrm{~nm}$ \\
\hline Split ratio & $1: 64$ & $1: 64$ \\
\hline Line code & NRZ & NRZ \\
\hline Max. Reach & $20 \mathrm{~km}$ & $20 \mathrm{~km}$ \\
\hline BER & $10^{-3}$ & $10^{-4}$ \\
\hline
\end{tabular}

In the simulations, NG-PON2 fairs significantly better than the new EPON solution with much lower BER and signal degradation in 1:16 and 1:32 split ratios. Signal degradation is also much lower for these splits as can be seen in Fig. 8 and Fig. 9.

Higher split ratios are according to the simulations easily achievable even for split ratios high as 1:128 for around $14 \mathrm{~km}$ fibre length without FEC. With FEC implementation higher fiber lengths would be more than likely achievable.

\section{CONCLUSION}

We have designed and compared simulations for NG-PON2 with transfer rates of $40 / 10 \mathrm{Gbit} / \mathrm{s}$ and $100 \mathrm{G} \mathrm{EPON}$ with transfer rates of $100 / 100 \mathrm{Gbit} / \mathrm{s}$. For $100 \mathrm{GEPON}$ we measured feasible BER values for split ratio up to 1:32 and fibre length of $20 \mathrm{~km}$. Higher split ratios suffered from too high BER in measured range of fibre lengths. In NG-PON2 simulation the BER values are significantly lower, allowing it the same range with 1:64 split ratio and 1:128 for fibre length of up to $14 \mathrm{~km}$.

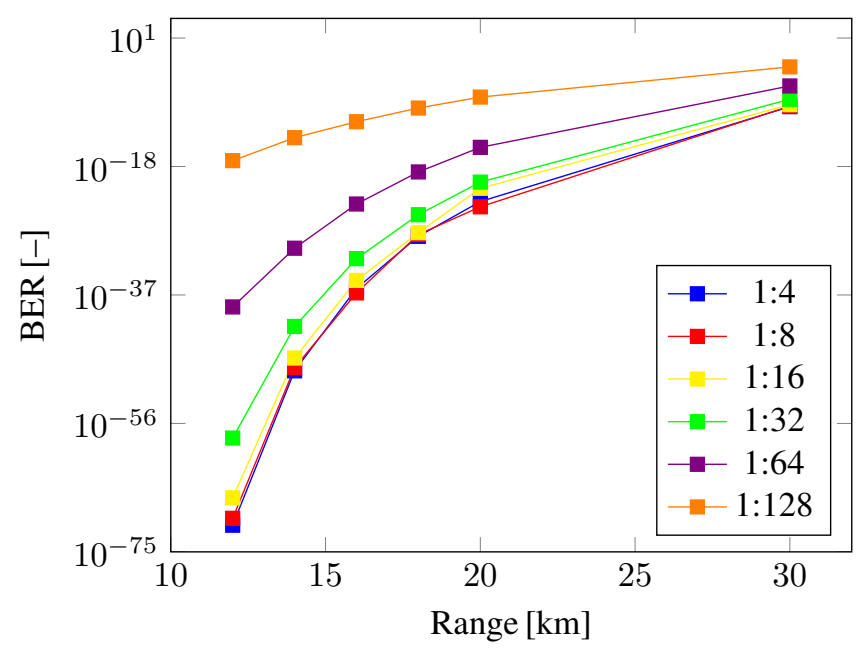

Fig. 8. BER Downstream Dependency on Reach in NG-PON2

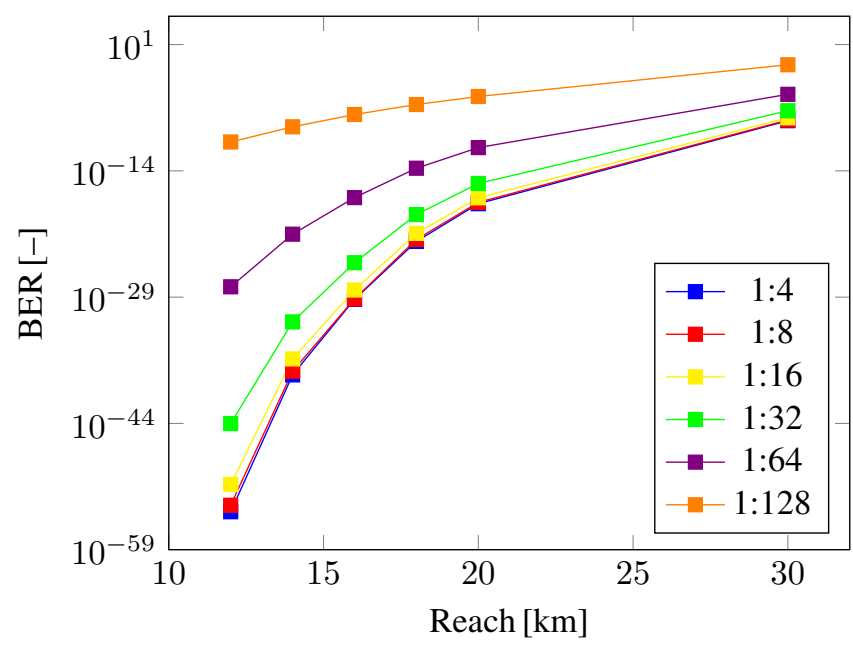

Fig. 9. BER Upstream Dependency on Reach in NG-PON2

In recent months, new information and decisions regarding 100G EPON standard came out. The most important information released were decisions regarding parameters of the standard not previously known during the time of writing. The task force includes parameters for the first two generations of the standard, the $25 \mathrm{G}$ and $50 \mathrm{G}$ EPON. Released parameters consist of wavelengths for both downstream and upstream, OLT and ONU transmitter and receiver parameters and both Line codes and a draft of FEC. With these information future simulations could now be more elaborate and show more realistic performance figures compared to the future final solution. Also according to the official task force information from spring 2018, both symmetric and asymmetric 100G EPON is no longer the objective of the P802.3ca task force [15].

Within the future work is to implement recently released standard parameters such as OLT and ONU transmitter and receiver, wavelengths for both downstream and upstream, 256B/257B line coding and Forward error codes to better simulate the $50 \mathrm{G}$ EPON standard. 


\section{ACKNOWLEDGEMENT}

Presented research has been supported by project of the Ministry of Interior under grant no. VI20172019072 registration, the National Sustainability Program under grant LO1401, and by project "E-infrastructure CESNET modernisation", registration no. CZ.02.1.01/0.0/0.0/16 013/0001797.

\section{REFERENCES}

[1] C. Knittle, IEEE $100 \mathrm{~Gb} / \mathrm{s}$ EPON, in Optical Fiber Communications Conference and Exhibition (OFC), 2016, 2016, p. 1-3.

[2] V. Houtsma, D. van Veen, and E. Harstead, Recent Progress on Standardization of Next-Generation 25, 50, and 100G EPON, Journal of Lightwave Technology, vol. 35, no. 6, pp. 1228-1234, Mar. 2017, DOI: 10.1109/JLT.2016.2637825.

[3] Z. Vujicic, A. Shahpari, B. Neto, N. Pavlovic, A. Almeida, A. Tavares, M. Ribeiro, S. Ziaie, R. Ferreira, R. Bastos, and A. Teixeira, Considerations on performance, cost and power consumption of candidate 100G EPON architectures, in 2016 18th International Conference on Transparent Optical Networks (ICTON), 2016, p. 1-6, DOI: 10.1109/ICTON.2016.7550683

[4] X. Miao, M. Bi, Y. Fu, L. Li, and W. Hu, Experimental Study of NRZ, Duobinary, and PAM-4 in O-Band DML-Based 100G-EPON, IEEE Photonics Technology Letters, vol. 29, no. 17, p. 1490-1493, Sep. 2017, DOI: $10.1109 /$ LPT.2017.2731372.

[5] Wei Wang, Wei Guo, and Weisheng $\mathrm{Hu}$, A fair and flexible dynamic wavelength and bandwidth allocation algorithm for IEEE 100G-EPON, in 2017 19th International Conference on Transparent Optical Networks (ICTON), 2017, pp. 1-4, DOI: 10.1109/ICTON.2017.8024891

[6] Z. Li, L. Yi, H. Ji, and W. Hu, 100-Gb/s TWDM-PON based on $10 \mathrm{G}$ optical devices, Optics Express, vol. 24, no. 12, pp. 12941-12948, 2016, DOI: $10.1364 /$ OE.24.012941.

[7] B. Lin, Y. Li, S. Zhang, and X. Tang, Asymmetrical TWDM-PON with $4 \times 25-\mathrm{Gb} / \mathrm{s}$ downstream DSB OFDM and $4 \times 10-\mathrm{Gb} / \mathrm{s}$ upstream OOK modulations, Optical Fiber Technology, vol. 26, pp. 206-210, 2015, DOI: 10.1016/j.yofte.2015.09.007.

[8] Lei Xue, L. Yi, H. Ji, P. Li, and W. Hu, First Demonstration of Symmetric 100G-PON in O-band with 10G-Class Optical Devices Enabled by Dispersion-Supported Equalization, in Optical Fiber Communication Conference, 2017, p. M3H.1-, DOI: 10.1364/OFC.2017.M3H.1.

[9] Y. Guo, Y. Yin, Y. Song, M. Huang, Y. Li, G. Kuang, Z. Fu, X. Huang, P. Cai, Z. Ma, M. Li, and D. Pan, Demonstration of $25 \mathrm{Gbit} / \mathrm{s}$ per channel NRZ transmission with $35 \mathrm{~dB}$ power budget using $25 \mathrm{G}$ Ge/Si APD for next generation 100G-PON, in Optical Fiber Communications Conference and Exhibition (OFC), 2017, 2017, p. 1-3.

[10] Lei Xue, L. Yi, H. Ji, P. Li, and W. Hu, Symmetric 100-Gb/s TWDMPON in O-Band Based on 10G-Class Optical Devices Enabled by Dispersion-Supported Equalization, in Journal of Lightwave Technology, vol. 36, pp. 580-586, 2018, DOI: 10.1109/JLT.2017.2777498.

[11] Amiri, I. S. et al. Increment of Access Points in Integrated System of Wavelength Division Multiplexed Passive Optical Network Radio over Fiber. Sci. Rep. 5, 11897; DOI: 10.1038/srep11897 (2015)

[12] Harstead E., D. v. Veen, V. Houtsma, J. Johnson 25G/50G/100G EPON wavelength plan C, -IEEE P802.3ca 100G-EPON Task Force-, in IEEE P802.3ca 100G-EPON Task Force: Meeting Materials, 2016. [Online]. Available: http : //www.ieee802.org/3/ca/public/meeting rchive /2016/09/harstead ${ }_{3} \mathrm{ca}_{3} b_{0} 916 . p d f$

[13] Tejkal V., M. Filka, J. Sporik, P. Reichert, P. Munster, The influence of binary modulations in passive optical network based on WDM, in 2011 34th International Conference on Telecommunications and Signal Processing (TSP), 2011, DOI: 10.1109/TSP.2011.6043755.

[14] C. Knittle, M. Huang, A. Umnov, H. Lee, D. Liu, D. Zhang, G. Kramer, E. Harstead, V. Houtsma, E. Dai, D. Remein, J. Johnson, N. Tanaka, and F. Effenberger, IEEE P802.3ca 100G-EPON Task Force, in IEEE P802.3 ca 100G-EPON Task Force: Meeting Materials, 2016.

[15] P802.3ca Task Force Proposals and Technical Motions website. [Online]. Available: http //www.ieee802.org/3/ca/public/living ocuments/motions.shtm

[16] VPIphotonics website. [Online]. Available: http //www.vpiphotonics.com/

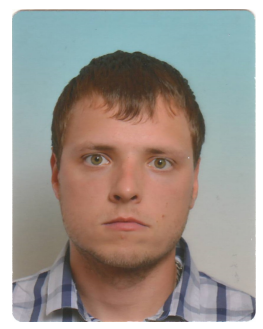

Tomas Horvath (MSc, $\mathrm{PhD})$ was born in Havirov, Czech Republic in 1989. He is a young researcher at Brno University of Technology and a researcher at CESNET. He received his $\mathrm{PhD}$ degree in communications and informatics from Brno University of Technology in 2017. His record shows more than 33 peer reviewed proceedings and journal papers. His current research interests include software-defined optical networking, passive optical networks, and sensing.

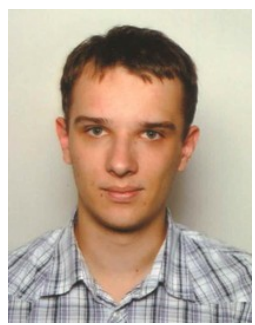

Jan Chlapek (BSC) is a student at Brno University of Technology in Master's programme Communications and Informatics. He received his BSc degree in 2017. In his Bachelor thesis he worked on simulation of high-speed access networks, especially the NGPON2 and 100G-EPON standards according to ITU$\mathrm{T}$ and IEEE, respectively.

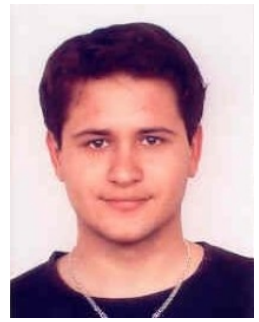

Petr Munster (MSc, Ph.D.) received his engineering degree from The Faculty of Electrical Engineering and Communication at Brno University of Technology in 2010 and Ph.D. in 2014. Currently, he is involved in research at Brno University of Technology and his research interests include fiberoptic communications and sensors. He is author or co-author of more than 50 scientific publications in journals and conference proceedings.

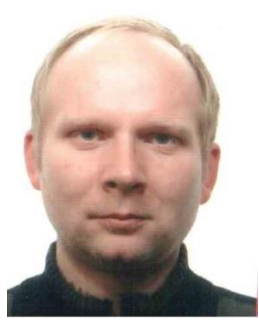

Josef Vojtech is a head of research department of Optical networks at CESNET a.l.e., operator of national research and education e-infrastructure of the Czech Republic. He received his MS and BS degrees in computer science and pedagogy from the Czech Technical University in 2001 and 2003, respectively, and his $\mathrm{PhD}$ degree in field of optical networking from the Czech Technical University in 2008. His record shows more than 65 peer reviewed proceedings and journal papers. He holds 18 patents (including US and EU) and utility models. He participated in international projects: COMPLETE, FI-PPP XIFI, GN4, GN3+ GN3, GN2, Porta Optica Study and SEEFIRE. His current research interests include software defined optical networking and special photonic services as precise time, stable frequency or sensing. He is a member of SPIE, IEEE and OSA. In 2007 he received the Research prize of the Czech minister of education.

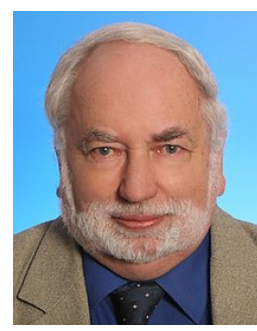

Miloslav Filka (prof.) was born in 1946 in Brno, Czech Republic. Since 2010 he has been a professor at the Department of Telecommunications at the Brno University of Technology. He is a leader of the optical group OptoLab and also a head of the Laboratory of transmission media and optical networks. He is a member of a several institutes (e.g. Institute of Electrical Electronics Engineers) and is also a committee of many conferences (International Conference Telecommunications and Signal Processing, International Conference New Information and Multimedia Technologies). His current research themes focus on fiberoptic telecommunications, especially FTTx technologies. 